\section{AGEING IN MAN AND OTHER 5o. ANIMALS}

$\mathrm{O}$ July 16 at the Technolqs, Loparn a conference was held by the British B arlue thp Cly bfor Research on Ageing. Delegates of ku ropern lat nes of the Club and some other gqests interested in the subject "were also present. 20 ord Nuffield was elected honorary president of to conference, and Sir Francis Fraser, chairman of the conference.

Sir Francis Fraser introduced the delegates from other countries. He then proceeded to describe the role of clinical research on old age. Clinical research is the most difficult of all fields of research as there are always so many uncontrolled factors to consider. Quick results are not to be expected; one must think in terms of long-continued and laborious research. Pathological conditions are generally present in addition to old age, and it is difficult to differentiate between them. He concluded that clinical research on physiological ageing is practically impossible, and that it is better for clinicians to concentrate on studying primarily the pathological conditions.

Prof. F. A. E. Crew gave an account of recent work in Scotland on the sociological problems of an ageing population. The current figures for births, deaths and marriages appear satisfactory on the surface, but when looked into more carefully the present population trend shows a most disquieting increase in the proportion older than sixty-five. Since industrial capacity diminishes after the age of thirty-five there is a danger of the old becoming a burden on the younger members of the community. He went on to analyse the statistical figures of the causes of death, and he urged the need for closer collaboration between clinical investigators and those working on population research. The real problem of gerontology" is "not how to give years to life, but life to years".

Dr. M. Critchley urged the need for further research on the nervous system in the study of normal ageing as well as the associated pathological conditions. He outlined in detail a number of possible schemes of research of importance for neuro-gerontology.

Dr. V. Korenchevsky expressed the aim of geron. tology as not merely to achieve a longer life, but a stronger one. Since ageing starts at a very early age, we must include the study of the whole life-span and even the development of the fœtus. Attempts that had been made at rejuvenation by such methods as Voronoff's glandular grafts, treatment with hormones or Bogomolets' serum, have proved unsatisfactory, since they achieve only a temporary stimulation : the aim must be to discover and remover the causes of premature ageing and not merely to stimulate degenerated tissues. He outlined five conditions required for international and local organisation, if research on ageing is to progress at a reasonable rate.

Prof. F. C. Bartlett believed that the effects of ageing on psychological performance can be compared with the effects of other factors such as extremes of heat, humidity and noise. Each of these factors produces an increased liability to fatigue, which can be measured in a number of ways. New methods developed for the study of skill and fatigue in air pilots during the War may be applicable.

In the discussion which followed these papers, Prof. G. R. Cameron emphasized the need for quantitative research on the effects of ageing on the blood vessels of the brain : there is scope for the employment of many new techniques on this problem. Lord Nuffield said he could not understand how ageing could begin in early childhood, since the athletic performance of a child goes on improving up to the age of fifteen. Dr. Korenchevsky and Dr. J. Hammond pointed out in reply that different organs develop at different ages: brain and bone have priority at an early age, and muscle develops only later. Prof. M. J. Stewart would like research to be carried out on changes in the blood in old age : it is a striking fact that many old people die of pneumonia because their blood fails to respond as vigorously as that of young people to the toxins of the pneumococcus. Dr. D. Richter urged the need for more accurate statistics of the causation of death. The present figures are unreliable, as permission for a post-mortem is often refused. The public must be educated into a realization of the importance and value of post-mortem examinations. The development of gerontology as a science can be seen in the two editions of Cowdry's book on ageing. The first edition was made up largely of speculation and poetry : the second edition contained less poetry, but more facts, figures, tables and measurements. Clinical science can help in the same direction by obtaining greater precision in defining and measuring the factors concerned. Dr. L. Fairfield deplored the way in which the chronic sick and aged are despised by the teaching hospitals and thrust on the public authorities. Medical science has relieved many of the worst miseries of old age, such as the bladder and prostate troubles; but senile dementia is a social problem of increasing urgency. Is it right that healthy young women, who should be bringing up children in their own homes, are now engaged in washing the dirty linen in wards of senile dements?

The guests from Sweden, Denmark, Holland and France then reviewed the work on ageing that is in progress in their respective countries. Dr. B. Purchase, who gave the point of view of a coroner, agreed as to the unreliability of the present statistics, and said he could provide reliable figures for some two thousand cases a year on which post-mortems have been carried out. Prof. Crew said he is anxious to close with Dr. Purchase's offer, as he has been trying to obtain experimental material of this kind. Dr. Fairfield considers that the apparent conspiracy among general practitioners to avoid putting cancer on death certificates might be sufficient to make a significant error in the figures.

The morning session was closed by the passing of five resolutions proposed by Dr. Korenchevsky and expressing the views of the conference as to the requirements for the further rapid advance of gerontology. These included international co-operation between those interested in the subject (for which purpose the Club was founded), establishment of permanent institutes for research on ageing and the provision of ample funds necessary to secure these facilities.

At the afternoon session Dr. P. C. Williams read a paper for Prof. E. C. Dodds on the significance of androgen and œstrogen excretion in the urine in relation to ageing. The tendency to cancer of the prostate is considerably affected by the sex hormone balance, as shown by experiments on castration and by the effects of administering stilbœstrol in the male. There is a need for further quantitative data on all age groups.

Prof. Crew pointed out that the male infant has a 
much poorer chance of survival than the female. A male infant with broncho-pneumonia is thus suffering from two conditions: (a) broncho-pneumonia and (b) maleness. Could we use sex hormone preparations to effect a temporary transformation of a male infant into a female to get over this disadvantage ?

Dr. Hammond deseribed recent work at Cambridge on the ageing of the fœetus in rabbits and sheep. The chronological age must be differentiated from the physiological age, as measured by the size, the ossification of the bones and development of the heatregulating centres. The physiological ageing of the fotus can be varied experimentally by controlling the size of the litter and the nutrition of the mother. $\mathrm{He}$ suggested that similar factors may operate in the return to an infantile condition in old age.

Prof. J. B. Duguid put forward a new theory of the thickening of the arteries in atherosclerosis. $\mathrm{He}$ believes that we have been misled by the teachings of the Virchows. The thickening does not come from within the artery walls : it is due to the organisation of successive layers of fibrin deposited on the intima. The difference is fundamental, since in his view the primary cause of the disease is in the blood rather than in the vessels. Prof. Cameron asked how this view could account for lipoids in atheromatous plaques. If the arterial narrowing is due to encrustation with fibrin from without, why do not the veins get narrowed in the same way? Prof. Duguid replied that the relation of lipoid changes to atheroma is not fully understood. The veins do not get narrowed, because when they are thrombosed the whole vein becomes blocked, while in an artery, the vessel is cleared by the rapid flow of the blood.

Dr. Korenchevsky gave an account of experiments on the artificial premature 'climacteric' and its effects on the process of ageing in female rats, and the influence on this process of androgenic, œstrogenic and thyroid hormones. Ovariectomy hastens the ageing of rats. The combination of androgenic, œstrogenic and thyroid hormones together produces an apparent 'anti-ageing' effect, as judged by the organ weights and histological appearances of some vital organs; but this may be merely a temporary stimulation of ageing organs. Prolonged treatment may be followed by collapse, since the stimulants do not remove the causes of ageing.

Dr. W. Stephenson read a paper for Dr. P. E. Vernon on the psychological conclusions from an investigation of the effects of vitamins on senile patients at Tooting Bec Hospital. It was concluded that large amounts of vitamins exert little effect on psychological ageing, when the diet is adequate in these compounds. Dr. Stephenson described also some work of his own in which an increased amount of vitamins in a diet previously deficient in these substances was followed by an improvement in the mental capacity of senile subjects. Prof. Bartlett criticized the use of psychometric tests in these experiments, as he holds that the performance of such a test is not characteristic of senile subjects. It would be better to measure the kind of things that old people normally enjoy doing.

Dr. Richter described an investigation on the biochemical changes in ageing. The results indicate that the mental and physical deterioration in ageing are different processes that can be defined by their biochemical accompaniments. Biochemical changes are found in the blood in advanced physical senility which are distinct from the changes normally occurring in old age: the changes associated with senile dementia are different again. Senility is not a simple entity, but is made up of a series of pathological processes, which should be more clearly defined by further work. Our ignorance of the biochemical changes in the tissues in ageing is a big gap in our knowledge. Much public money is now being spent on palliative measures in providing homes for old people : there is an urgent need that more should be spent on preventive measures, which means research.

Dr. J. H. Smyly gave an account of the methods developed by him for assessing physical fitness in old men. These included exercise tolerance tests as measured by pulse-rate and oxygen consumption. The usual methods may be dangerous for old people.

Prof. Crew, in summing up, said that the proportion of old people in the population is increasing, and gerontology is therefore a science of increasing social importance. Geriatrics must also come to occupy a part not less important in medicine than pediatrics to-day. He recommended the formation of a permanent international congress committee to organise international gerontological congresses.

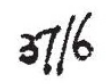

\section{MIMETIC POLYMORPHISM}

\author{
By Prof. G. D. HALE CARPENTER, M.B.E. \\ University Museum, Oxford
} R. RICHARD/T LoLDSCHMIDT has dis-
cussed Chaptel of Darwinfort (luart. Rev. Biol., 20 ;

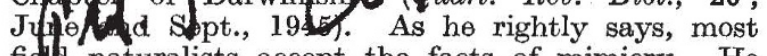
fiell naturalists accept the facts of mimiery. He returns to the theory of production of a mimetic resemblance by saltations, but the discussion, being mainly on the genetical basis, ignores the fact that mimicry is essentially a phenomenon of life, and that far-reaching conclusions drawn from the study of the colour and pattern of a few dried butterflies do not cope with a vast number of cases among other creatures. Indeed, he remarks that in view of conflicting evidence as to habits, etc., of mimetic butterflies, it is better to mark this group of doubtful adaptations as non liquet. Were Goldschmidt more familiar with at least the records of field entomology, he would have found very many observations from naturalists of experience who have been deceived against their better judgment. The resemblance of an ant-like spider to its model is notorious for the part played by special movements and attitude, both foreign to the generality of spiders. The deceptive resemblance of longicorn beetles to Hymenopterous models (Braconidæ) is so great that experienced collectors have recorded their inability to distinguish them in flight. A black fossorial wasp in tropical America has the habit, while very actively running about on the ground, of vigorously flicking its wings. This characteristic is copied by two other insects far removed in relationship, a Reduviid (Hemiptera) and a Tettigoniid grasshopper which, agreeing in their wholly black coloration with the wasp, have the same habit, completely foreign to their congeners. Quite recently I was told by a leading Brazilian naturalist of how he was warned by an entomological companion not to touch a certain black insect as it stung very badly : the insect was the mimetic grasshopper.

The fact that mimicry sometimes does not deceive is of little importance beside the fact that sometimes 